\title{
A case of benign hereditary telangiectasia without family history ${ }^{*}$
}

\author{
Priscila Regina Orso Rebellato ${ }^{1}$ \\ Bruno Tadeu Stella ${ }^{2}$
}

\author{
Luis Eduardo Agner Machado Martins ${ }^{1}$ \\ Michelle Cristine Tokarski ${ }^{1}$
}

Dear Edito,

A 60-year-old white female patient sought treatment for asymptomatic erythematous-telangiectasia macules on her upper limbs, back, abdomen, thighs, neck, and lips (Figures 1 and 2). The condition started at 7 years of age. Her lower limbs showed no skin alterations, and she never developed mucosal nor visceral bleeding. Darier's sign was negative. She suffered from hypertension and type II diabetes mellitus; atenolol, hydrochlorothiazide, furosemide, and metformin were used for treatment. She denied skin lesions in other family members, including her only daughter. She had quit smoking, had no history of alcohol abuse, and had reached menopause at the age of 45 . Histopathological examination performed on her skin (back and left shoulder) showed preserved epidermis, dilated superficial dermal blood vessels, mild lymphocyte reaction, and absence of mast cells (Figure 3). Lab tests - e.g., complete blood

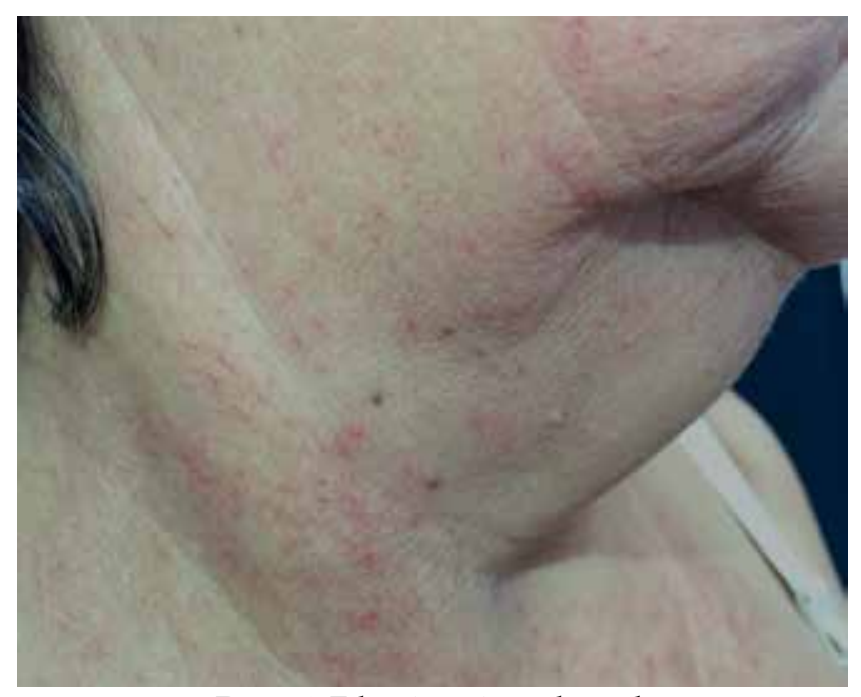

FIGURE 1: Telangiectasia on the neck count, renal and liver function - were normal. Based on these results, we diagnosed benign hereditary telangiectasia, despite the absence of family history. Once the benign nature of the lesions was verified, we proposed intense pulsed light as a treatment for aesthetic purposes.

Telangiectasias are abnormal dilations of the terminal vessels of the subpapillary plexus in the superficial dermis. They might be associated with systemic diseases, such as lupus erythematosus, dermatomyositis, scleroderma, cutaneous mastocytosis (telangiectasia macularis eruptive perstans), cirrhosis, pregnancy, and angiotropic lymphoma. They may also be associated with inherited diseases, such as ataxia telangiectasia, hereditary hemorrhagic telangiectasia (Rendu-Osler-Weber syndrome), and benign hereditary telangiectasia (BHT). ${ }^{1}$

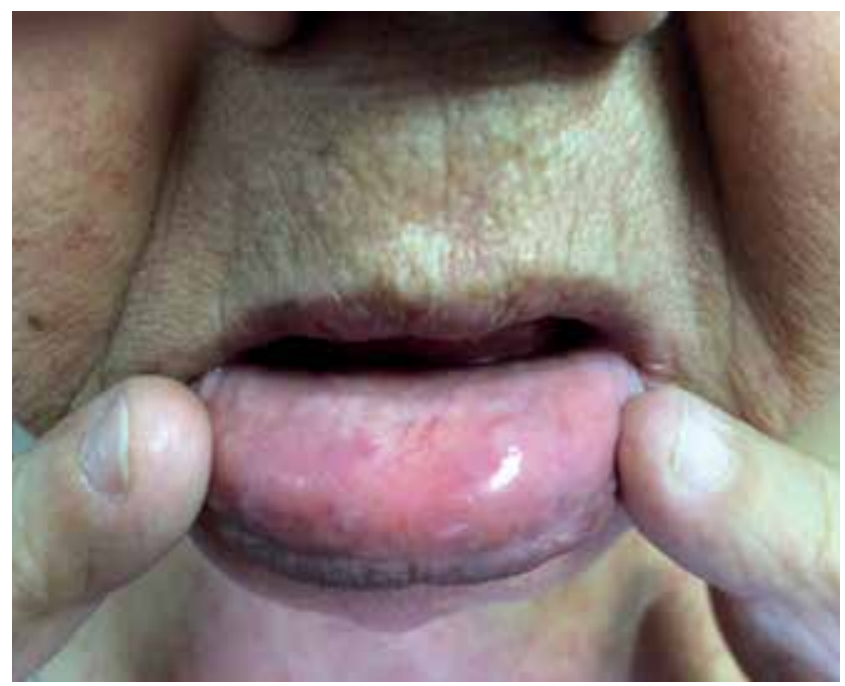

Figure 2: Telangiectasia on the lips and oral mucosa

\section{Received on 05.03.2015}

Approved by the Advisory Board and accepted for publication on 08.08.2015

* Work performed at the outpatient facility at Hospital Universitário Evangélico de Curitiba - Faculdade Evangélica do Paraná (HUEC-Fepar) - Curitiba (PR), Brazil. Financial Support: None.

Conflict of Interest: None.

1 Faculdade Evangélica do Paraná (Fepar) - Curitiba (PR), Brazil.

Universidade Federal do Paraná (UFPR) - Curitiba (PR), Brazil.

(2017 by Anais Brasileiros de Dermatologia 


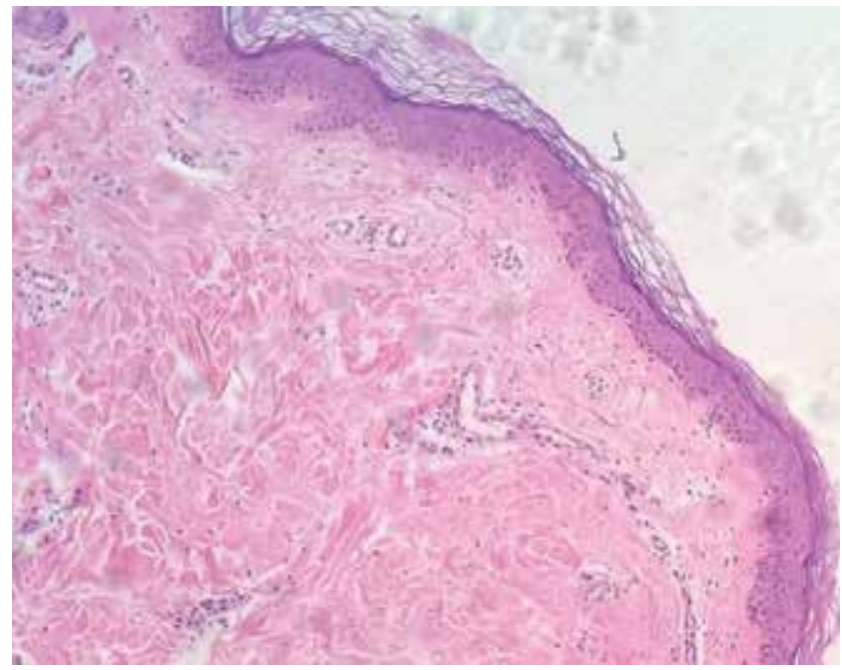

Figure 3: Preserved skin, superficial dermis with dilated vessels, and mild lymphocyte reaction

BHT is an inherited dermatosis characterized by the presence of telangiectasia on the skin and lips. It is a rare infection of unknown cause and autosomal dominant inheritance. It is an idiopathic or primary telangiectasia, developed during childhood, possibly at birth, without systemic lesions. ${ }^{2}$

Clinically evaluation shows multiple telangiectasias randomly disseminated in the integument, including the vermilion of the lips. In the early phases, the lesions are small and red, usually increasing in size and becoming brighter over the years. ${ }^{1,2}$ They are asymptomatic without systemic involvement. ${ }^{3}$

Main differential diagnoses include: hereditary hemorrhagic telangiectasia with mucosal and visceral cutaneous lesions associated with pathological bleeding; generalized essential telangiectasia affecting primarily the lower extremities in women with 40-50 years of age; spider angiomas, usually found in pregnant women and patients with liver diseases; unilateral nevoid telangiectasia with skin and mucosal lesions, showing unilateral distribution along a dermatome; and telangiectasia macularis eruptiva perstans caused by the massive infiltration of mast cells in the upper dermis with dilated capillaries, shown in anatomopathology through specific staining. ${ }^{4,5}$

BHT histology shows preserved skin and dilated blood vessels in the superior dermis.1 This case presented all abovementioned findings. Hereditary hemorrhagic telangiectasia is different from BHT, as the capillary walls in the latter get thicker, which explains the absence of hemorrhagic phenomena. ${ }^{1,2}$

Brancati et al. ${ }^{1}$ performed a genetic study of an Italian family with 13 members affected by BHT over three generations. Their autosomal dominant inheritance showed complete penetrance, and the study found a genetic variant in the $7 \mathrm{Mb}$ region on chromosome 5q14, called CMC1.

As described by Cai et al. ${ }^{3}$ and Nakajima et al. ${ }^{4}$, we report a case of BHT without family history, suggesting that this dermatosis might occur sporadically. Luiti et al. ${ }^{5}$ have recently reported the first case of BHT in the literature without family history in monozygotic twins.

Due to a lack of resources, our hospital failed to perform a genetic study of this case. Therefore, it is unclear whether a genetic mutation occurred. Despite this fact, our clinical diagnosis remains confirmed. Further studies focusing on the genetic aspect of BHT cases should be performed in order to improve our understanding of its means of transmission.

There is no effective treatment to prevent telangiectasia Being a benign condition, presenting no health risks, except for aesthetic nuisance, laser treatments and intense pulsed light are recommended treatments. ${ }^{3}$

\section{REFERENCES}

1. Brancati F, Valente EM, Tadini G, Caputo V, Di Benedetto A, Gelmetti C, et al. Autosomal dominant hereditary benign telangiectasia maps to the CMC1 locus for capillary malformation on chromossome 5q14. J Med Genet. 2003;40:849-53.

2. Gontijo B, Pereira LB, Silva CMR. Malformações vasculares. An Bras Dermatol. 2004; 79:7-25.

3. Cai L, Sun QM, Zang DJ, Zhang JZ. Hereditary benign telangiectasia without family history in China. Chin Med J. 2011; 124:795-6.

4. Nakajima I, Okuyama R, Terui T, Tagami H, Aiba S. The first report of non-hereditary benign telangiectasia. J Eur Acad Dermatol Venereol. 2006;20:1329-31.

5. Liuti F, Almeida PJ, Borrego L, Montenegro T. Hereditary benign telangiectasia in monozygotic twins with no family history. Int J Dermatol. 2015;54:e95-6

\author{
MAILING ADDRESS: \\ Priscila Regina Orso Rebellato \\ Alameda Doutor Carlos de Carvalho, 1652 \\ Bairro Batel \\ 80730-200 Curitiba, PR - Brazil \\ E-mail:prirebellato@yahoo.com.br \\ hd330@yahoo.com \\ bruno.t.s.81@hotmail.com \\ mitorarski@hotmail.com
}

How to cite this article: Rebellato PRO, Martins LEAM, Stella BT, Tokarski MC. A case of benign hereditary telangiectasia without family history. An Bras Dermatol. 2017;92(1):162-3. 